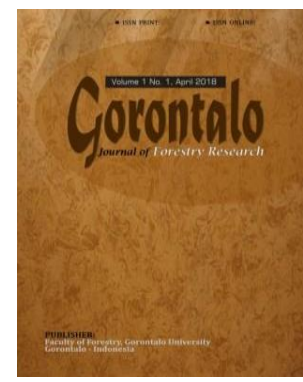

Gorontalo

Journal Of Forestry Research

Volume 3 Nomor I April 2020

P-ISSN 2614-2058; E-ISSN 2614-204X

\title{
INVENTARISASI HASIL HUTAN BUKAN KAYU DARI TANAMAN MPTS DI HUTAN DESA SUKARAJA KPH RAJABASA
}

\author{
Inventarisasi of Non-timber Forest Product from \\ Multi Purpose Tree Species in Sukaraja Forest \\ Village KPH Rajabasa
}

\author{
Ani Fitriyani, Melya Riniarti, Duryat \\ Jurusan Kehutanan, Fakultas Pertanian, Universitas Lampung \\ E-mail : aani9611@gmail.com
}

\begin{abstract}
ABSTRAK
Hutan Desa Sukaraja merupakan hutan lindung yang dimanfaatkan oleh masyarakat melalui pengelolaan dengan sistem agroforestri dan pemungutan hasil hutan bukan kayu untuk meningkatkan kesejahteraan masyarakat. Penelitian ini bertujuan untuk memperoleh data mengenai jenis dan jumlah HHBK dari tanaman MPTs serta menduga potensi HHBK dari tanaman MPTs pada masa yang akan datang berdasarkan ketersediaannya di masa kini. Data dikumpulkan melalui analisis vegetasi pada 29 plot contoh yang diambil berdasarkan metode SRS (Simple Random Sampling). Untuk memprediksi penambahan jumlah MPTs 1 sampai 4 tahun yang akan datang dilakukan pengamatan pohon pada fase tiang dan pancang. Hasil penelitian menunjukkan terdapat 11 jenis tanaman MPTs yang dimanfaatkan hasil hutan bukan kayunya oleh masyarakat Desa Sukaraja yaitu durian, cengkeh, pala, petai, alpukat, kemiri, mangga, nangka, jengkol, melinjo dan duku. Hasil penelitian menunjukkan bahwa hingga beberapa tahun yang akan datang pohon cengkeh dan durian masih menjadi MPTs yang paling banyak dimanfaatkan dan ditanam oleh masyarakat. Sedangkan mangga dan kemiri merupakan HHBK yang produksinya akan stagnan atau bahkan mengalami penurunan dalam kurun waktu 1-4 tahun yang akan datang.
\end{abstract}

Kata Kunci : HHBK; MPTs; Hutan Desa; KHP Rajabasa

\begin{abstract}
Sukaraja Village Forest is a protected forest that is utilized by the community through agroforestry system and collection of non-timber forest products to improved community welfare. This study aimed to obtain data on the types and numbers of NTFPs from MPTs and to estimate the potential of NTFPs from MPTs in the future based on their
\end{abstract}


availability in the present. Data was collected through vegetation analysis with 29 sample plots taken based on the SRS (Simple Random Sampling) method. To predict the increase of amount of MPTs in 1-4 years, observed of trees in the pole and sapling phases. The results showed that there were 11 types of MPTs that were utilized by nontimber forest products by the people of Sukaraja Village, that were Durio Zibethinus, Eugenis aromaticum, Phitecellobium lobatum, Parkia spesiosa, myristica fragnans, Artocarpus heterophyllus, Lansium domesticum, Persea americana, Alueuritas moluccanus, Gnetum gnemon and Mangifera indica. The results showed that for the next few years Eugenia aromaticum and Durio zibethinus trees were still the most widely used and planted by the community. While production of Mangifera indica and Alleurites moluccanus were the NTFPs that will be stagnate or even decline in the next 1-4 years.

Keywords : NTFPs; MPTs; Village Forest; KPH Rajabasa

\section{PENDAHULUAN}

Hutan desa menurut Peraturan Menteri Kehutanan Republik Indonesia No. P. 89/Menhut-II/2004 adalah hutan negara yang belum dibebani izin/hak, yang dikelola oleh desa dan dimanfaatkan untuk kesejahteraan desa. Berdasarkan peraturan tersebut, UPTD KPH XIII Gunung Rajabasa Way Pisang - Batu Serampok membentuk hutan desa yang bertujuan untuk meningkatkan kesejahteraan masyarakat sekitar hutan serta untuk mengurangi perambahan. Kini tercatat sebanyak 1.147 masyarakat yang tersebar di 22 desa pada empat kecamatan di Kabupaten Lampung Selatan telah memanfaatkan hutan desa tersebut yang dikelola dengan sistem agroforestri (KPHL, 2013).

Potensi kayu di KPH Rajabasa mencapai 139,32 $\mathrm{m}_{3}$ per hektar dan tergolong cukup tinggi (KPHL, 2013), akan tetapi karena KPH Rajabasa termasuk dalam wilayah hutan lindung maka pemungutan kayu tidak diperbolehkan (SK Menhut No. 367, 2011). Masyarakat yang memiliki ketergantungan terhadap hutan (Mulyana, dkk. 2017) tetap diperbolehkan mengelola hutan secara agroforestri melalui hutan desa. Masyarakat diperbolehkan menanam tanaman MPTs dan pemungutan HHBK.

UU No. 41 tahun 1999, menyatakan bahwa pemungutan HHBK yang dapat diambil dari hutan lindung antara lain berupa, rotan, madu, getah, buah dan jamur. Sumber lain menyebutkan bahwa HHBK adalah segala sesuatu yang bersifat material (bukan kayu) yang diambil dari hutan untuk dimanfaatkan dalam kegiatan ekonomi dan sebagai peningkatkan kesejahteraan masyarakat. HHBK umumnya merupakan hasil sampingan dari sebuah pohon, misalnya getah, daun, kulit, buah atau berupa tumbuhantumbuhan yang memiliki sifat khusus seperti rotan, bambu dan lain-lain (Departemen Manajemen Hutan, 2016).

Penelitian ini dilakukan untuk mengetahui jenis dan jumlah tanaman MPTs yang terdapat pada salah satu hutan desa di KPH Rajabasa. Berdasarkan penelitian Violita dkk. (2015) tanaman dominan di KPH Rajabasa antara lain melinjo, durian, jengkol, kemiri, teureup dan mindi. Penelitian Mulyana dkk. (2017) menemukan tanaman utama yaitu, kopi, kakao, pisang, yang dikombinasikan dengan tanaman lainnya yaitu alpukat, gintung, kahiyang, aren, jengkol, damar, pinang, lada, pala, bambu, randu, 
dadap, nangka, sonokeling, kemiri dan kaliandra. Penelitian ini bertujuan untuk memperoleh data mengenai HHBK serta menduga potensi HHBK dari tanaman MPTs yang terdapat di Hutan Desa Sukaraja, KPH Rajabasa pada masa yang akan datang berdasarkan pada ketersediaannya pada masa kini. Pentingnya mengetahui jenis HHBK dari Tanaman MPTs adalah dapat digunakan oleh pihak pengelola, masyarakat atau KPH sebagai dasar dalam pengambilan kebijakan mengenai keberadaan HHBK dari tanaman MPTs di Hutan Desa Sukaraja, KPH Rajabasa, seperti dalam menganalisis kemungkinan membuka usaha pengolahan salah satu jenis HHBK yang ada.

\section{METODOLOGI PENELITIAN}

\section{Alat dan Objek Penelitian}

Penelitian ini dilaksanakan pada bulan Maret 2019 di Hutan Desa Sukaraja, KPH Rajabasa, Kecamatan Rajabasa, Kabupaten Lampung Selatan. Alat yang digunakan adalah GPS (Global Position System), roll meter, tali rafia, patok dan lembar pengamatan. Objek dari penelitian ini adalah tegakan yang terdapat di Hutan Desa Sukaraja. Penelitian dilakukan dengan metode analisis vegetasi untuk mengetahui jenis dan jumlah penyusun vegetasi Hutan Desa Sukaraja. Plot pengamatan ditentukan secara acak, plot berbentuk petak dengan ukuran $20 \mathrm{~m}$ x 20m dan tanaman MPTs yang telah berproduksi sebagai objek penelitian. Penentuan sampel didasarkan pada populasi yang ada yaitu, berdasarkan Arikuntoro (2006) jika populasi lebih dari 100 orang maka sampel pengamatan yang dapat digunakan sebanyak 10-25\%. Pada penelitian ini sampel yang digunakan yaitu $20 \%$ dari total petani penggarap Hutan Desa Sukaraja (145 orang) maka diperoleh plot pengamatan sebanyak 29 plot yang diletakkan secara acak (Simple Random Sampling) dengan alasan bahwa masyarakat mengelola dengan sistem pengelolaan lahan yang sama yaitu agroforestri kompleks.

\section{Jenis Data}

Jenis data yang digunakan dalam penelitian ini adalah data primer dan data sekunder. Data primer meliputi jenis dan jumlah tanaman MPTs yang terdapat di lokasi penelitian yang diperoleh dari pengamatan langsung di lapangan serta produktivitas HHBK. Data sekunder adalah data yang berasal dari literatur atau sumber lain yang dapat menunjang penelitian, meliputi data nama tanaman.

\section{HASIL DAN PEMBAHASAN}

\section{Komposisi Jenis Vegetasi Penyusun Hutan Desa Sukaraja}

Berdasarkan SK No. 1656/Menlhk-PSKL/PKPS/PSL./3/2017 sebanyak $75 \%$ dari penduduk Desa Sukaraja berprofesi sebagai petani penggarap Hutan Desa Sukaraja. Dengan luas hutan kurang lebih 127 hektar, lahan tersebut 
dikelola atau digarap oleh 145 orang anggota LHPD. Lembaga Pengelola Hutan Desa (LPHD) Sukaraja membentuk 4 Kelompok Tani Hutan (KTH) yaitu KTH Tajur Hijau Lestari yang terdiri dari 50 anggota, KTH Tajur Lestari 39 anggota, KTH Tayas Makmur Jaya 26 anggota dan 30 anggota di KTH Tayas Lestari (SK Kepala Desa, 2015). Masing-masing anggota mengelola lahan dengan luas antara 0,5 hektar hingga 2 hektar. Pemberian izin pengelolaan lahan ini bertujuan untuk meningkatkan pendapatan petani, mengurangi perambahan serta diharapkan dapat meningkatkan kesadaran masyarakat terhadap kelestarian hutan (Simon, 2006).

Peraturan Kepala Desa Sukaraja (2015) menyebutkan masyarakat boleh menggarap lahan dengan cara mendaftar menjadi anggota LPHD kemudian anggota yang terdaftar diberi kartu anggota, lahan yang dikelola tidak dapat diwariskan atau dipindahtangankan. Sistem penanaman yang boleh dilakukan di Hutan Desa Sukaraja adalah dengan agroforestri. Indriyanto (2008) mengatakan bahwa agroforestri adalah menanam tanaman perkebunan bersama atau di bawah tegakan pohon pada waktu yang sama. Penanaman pohon wajib dilakukan agar tetap menjaga fungsi hutan sebagai kawasan lindung (Ginoga dkk., 2005). Penanaman pohon yang disarankan adalah pohon jenis MPTs. Pohon-pohon tersebut selain untuk menjaga fungsi hutan, juga agar masyarakat dapat memperoleh manfaat ekonomi dengan memanen produk yang dihasilkan selain kayu. Budidaya tanaman pangan di hutan seharusnya juga dapat diusahakan untuk tujuan komersial karena budi daya tanaman pangan di hutan tidak mengubah fungsi hutan sebagai penghasil jasa lingkungan (Puspitojati, 2011; Puspitojati, 2013) serta agar hutan dapat dimanfaatkan sebagai penghasil pangan (Nurrochmat dkk. 2012).

Hutan Desa Sukaraja dikelola dengan sistem agroforestri. Masyarakat menanam tanaman perkebunan bersama dengan tanaman MPTs. Sistem agroforestri diterapkan karena Hutan Desa Sukaraja termasuk dalam kawasan hutan lindung yang dilarang memanen hasil hutan kayu. Maka dari itu masyarakat menanam tanaman perkebunan dan tanaman MPTs yang dapat dipanen produk hutan selain kayunya. Jenis tanaman yang terdapat di Hutan Desa Sukaraja disajikan pada Tabel 1.

Tabel 1. Jenis Tanaman dan Nilai INP di Hutan Desa Sukaraja

\begin{tabular}{clllrrrrr}
\hline No & \multicolumn{1}{c}{ Nama } & \multicolumn{1}{c}{ Nama Ilmiah } & Sifat & \multicolumn{1}{c}{ K } & \multicolumn{1}{c}{ KR } & \multicolumn{1}{c}{ F } & \multicolumn{1}{c}{ FR } & INP \\
\hline 1 & Durian & Durio zibethinus & Intoleran & 28,45 & 15,79 & 1,14 & 15,79 & 31,58 \\
2 & Cengkeh & Eugenia aromaticum & Toleran & 15,52 & 8,61 & 0,62 & 8,61 & 17,22 \\
3 & Jengkol & Pithecellobium lobatum & Toleran & 13,79 & 7,66 & 0,55 & 7,66 & 15,31 \\
4 & Petai & Parkia spesiosa & Intoleran & 14,66 & 8,13 & 0,59 & 8,13 & 16,27 \\
5 & Pala & Myristica fragnans & Intoleran & 5,17 & 2,87 & 0,21 & 2,87 & 5,74 \\
& & Artocarpus & & & & & & \\
6 & Nangka & heterophyllus & Toleran & 0,86 & 0,48 & 0,03 & 0,48 & 0,96 \\
7 & Duku & Lansium domesticum & Intoleran & 1,72 & 0,96 & 0,07 & 0,96 & 1,91 \\
8 & Alpukat & Persea americana & Toleran & 3,45 & 1,91 & 0,14 & 1,91 & 3,83 \\
9 & Kemiri & Aleurites moluccanus & Intoleran & 5,17 & 2,87 & 0,21 & 2,87 & 5,74 \\
10 & Melinjo & Gnetum gnemon & Toleran & 0,86 & 0,48 & 0,03 & 0,48 & 0,96
\end{tabular}




\begin{tabular}{llllrrrrr}
\hline 11 & Manga & Mangifera indica & Toleran & 0,86 & 0,48 & 0,03 & 0,48 & 0,96 \\
12 & Pinang & Areca catechu & Toleran & 6,90 & 3,83 & 0,28 & 3,83 & 7,66 \\
13 & Sonokeling & Dalbergia latifolia & Semi & 2,59 & 1,44 & 0,10 & 1,44 & 2,87 \\
14 & Kopi & Coffea arabica & Intoleran & 33,62 & 18,66 & 1,34 & 18,66 & 37,32 \\
15 & Kakao & Theobroma cacao & Intoleran & 25,00 & 13,88 & 1,00 & 13,88 & 27,75 \\
16 & Ki Hujan & Samanea saman & Toleran & 0,86 & 0,48 & 0,03 & 0,48 & 0,96 \\
17 & Lada & Piper nigrum & Toleran & 12,07 & 6,70 & 0,48 & 6,70 & 13,40 \\
18 & Wareng & Gmelina arborea & Semi & 1,72 & 0,96 & 0,07 & 0,96 & 1,91 \\
19 & Cempaka & Michelia champaca & Intoleran & 0,86 & 0,48 & 0,03 & 0,48 & 0,96 \\
20 & Pisang & Musa padisiaca & Intoleran & 6,03 & 3,35 & 0,24 & 3,35 & 6,70 \\
\hline
\end{tabular}

Sumber : Data primer 2019

$\begin{array}{lllll}\text { Keterangan : } & \text { K } & \text { : Kerapatan (Individu) } & \text { KR } & \text { : Kerapatan Relatif (\%) } \\ & \text { F } & \text { : Frekuensi (Individu) } & \text { FR } & \text { : Frekuensi Relatif (\%) } \\ & \text { INP } & \text { : Indeks Nilai Penting (\%) } & & \end{array}$

Hutan Desa Sukaraja adalah bagian dari kawasan hutan lindung yang ada di Provinsi Lampung. Berdasarkan UU No. 5 Tahun 1967, hutan lindung adalah kawasan hutan yang karena keadaan sifat alamnya diperuntukkan guna mengatur tata-air, pencegahan bencana banjir dan erosi serta pemeliharaan kesuburan tanah yang perlu dipertahankan dan dilindungi. Apabila hutan lindung diganggu hingga kehilangan fungsinya, maka dapat menimbulkan bencana alam. Akan tetapi terdapat batas-batas tertentu yang dapat dimanfaatkan hasil hutannya tanpa harus mengurangi fungsinya sebagai hutan lindung. UU No. 6 Thn 2007 menyebutkan, pemanfaatan hutan pada kawasan lindung dapat dilakukan melalui kegiatan pemanfaatan kawasan, pemanfaatan jasa lingkungan dan pemungutan hasil hutan bukan kayu. Di Hutan Desa Sukaraja kegiatan pemafaatan hutan dilakukan dengan pemungutan HHBK melalui pembagunan hutan desa. Sistem penanaman yang diterapkan di Hutan Desa Sukaraja adalah dengan multistrata tajuk yang bertujuan untuk mengoptimalkan ruang tumbuh agar dapat memaksimalkan produktivitas..Salah satu cara yang digunakan yaitu dengan penanama jenis pohon dengan sifat toleransi yang berbeda.

Sifat toleransi tanaman merupakan kemampuan yang dimiliki tanaman terhadap intensitas radiasi matahari untuk mendapatkan pertumbuhan yang optimal (Indriyanto,2013). Sifat toleran adalah kemampuan tanaman yang dapat tumbuh baik dan berproduksi di bawah naungan pohon lain (Nugroho, 2011). Semi toleran adalah sifat pohon yang membutuhkan naungan pada saat masa pertumbuhannya, dan setelah dewasa tidak lagi membutuhkan naungan (Susanto, 2011). Sedangkan tanaman yang dapat tumbuh dengan baik apabila tidak ternaungi dan mendapatkan penyinaran cahaya matahari sepanjang hari adalah jenis tanaman dengan sifat intoleran (Indriyanto, 2013).

Ciri tanaman toleran adalah dapat melakukan permudaan sendiri di bawah naungan pohon lain, dapat membentuk tegakan bawah, memiliki tajuk tebal, pembersihan cabang atau ranting terjadi secara perlahan dan 
umumnya batang berbentung kerucut (Chairudin, 2015). Sedangkan pohon intoleran adalah pohon yang hanya akan mempermuda diri di daerah yang terang dan terbuka, akan lebih cepat mati bila terdapat naungan diatasnya, memiliki tajuk tipis, pembersihan cabang cepat dan cabang cenderung berbentuk silindris (Kualita, 2017).

Fiqa dan Laksono (2013) menyebutkan, jenis-jenis tanaman pada sistem agroforestri yang dapat digunakan di strata tertinggi adalah durian (Durio zibethinus), strata tengah adalah melinjo (Gnetum gnemon), dan strata terendah adalah rumput gajah (Pennisetum purpureum). Di wilayah Hutan Desa Sukaraja, jenis yang memiliki tajuk intoleran dan merupakan jenis tanaman strata tertinggi adalah durian (Durio zibethinus), kemiri (Alerites moluccanus) (Susanto, 2002) dan duku (Lansium domesticum). Sedangkan pohon semi toleran yang terdapat di Hutan Desa Sukaraja adalah yaitu sonokeling (Dalbergia latifolia) (Indriyanto, 2013) dan pohon toleran adalah melinjo (Gnetum gnemon), wareng (Gmelina arborea), mangga (Mangifera indica), alpukat (Rukmana, 2004) dan jenis-tumbuhan bawah di Hutan Desa Sukaraja.

Akan tetapi, toleransi tanaman tidak selalu konstan pada semua keadaan, beberapa hal yang mempengaruhi toleransi tanaman adalah umur, kekeringan, kesuburan dan garis lintang. Semakin tua umur suatu pohon, maka sifat pohon semakin intoleran, begitu pula dengan kekeringan dan garis lintang, semakin kering lahan dan semakin jauh garis lintang maka pohon semakin intoleran. Berbanding terbalik dengan tingkat kesuburan, semakin subur suatu lahan maka sifat pohon akan semakin toleran terhadap naungan. Hal ini dikarenakan kondisi pohon yang telah terpenuhi nutrisinya (Kurniawan, 2018).

Jenis tanah di KPH Rajabasa adalah andosol coklat (RPHJP, 2013) yaitu jenis tanah subur yang memiliki banyak kandungan bahan organik (Darmawijaya, 1990). Sifat kimia dari tanah andosol yaitu masam hingga netral (pH 5,0-6,5) (Soil Survey Staff, 2010). kandungan C dan N tinggi tetapi rasio $\mathrm{C} / \mathrm{N}$ rendah, kandungan kalium $(\mathrm{K})$ sedang, kandungan fosfor $(\mathrm{P})$ rendah (Prasetyo, 2005) dan kandungan bahan organik pada lapisan atas 5-20\%. Tanah andosol terbentuk di wilayah dataran tinggi lebih dari 1000 mdpl yang memiliki curah hujan antara 2.500-7000 mm/tahun, tanah andosol dapat menyerap air dalam jumlah banyak. Sifat tanah andosol umumnya peka terhadap erosi (Sartohadi dkk., 2012). Produktivitas tanah ini sedang hingga tinggi (Rahmat, 2009). Tanah andosol berwarna hitam, kelabu sampai coklat tua, teksturnya debu, lempung berdebu sampai lempung, dan strukturnya remah, Tanah andisols ini juga berpotensi untuk tanaman semusim maupun tahunan selain itu dapat untuk tanaman palawija dan padi ataupun untuk hutan lindung.

\section{Jenis-jenis Tanaman MPTs di Hutan Desa Sukaraja}

Pohon MPTs adalah jenis pohon yang disarankan penanamannya oleh pemerintah dalam membangun dan memanfaatkan kawasan hutan lindung. Hal ini karena pohon jenis ini dapat menghasilkan hasil hutan bukan kayu yang dapat dimanfaatkan oleh masyarakat untuk meningkatkan pendapatan tanpa harus melakukan penebangan. Di Hutan Desa Sukaraja dari 20 jenis 
tanaman yang tumbuh terdapat 11 jenis MPTs yang dimanfaatkan oleh masyarakat. Daftar tanamam MPTs dapat dilihat pada Tabel 2.

Tabel 2. Tanaman MPTs yang terdapat pada Hutan Desa Sukaraja

\begin{tabular}{llllc}
\hline No. & Lokal & \multicolumn{1}{c}{ Nama Ilmiah } & \multicolumn{1}{c}{ Famili } & $\begin{array}{l}\text { Bagian yang } \\
\text { dimanfaatkan }\end{array}$ \\
\hline 1 & Durian & Durio Zibethinus & Bombacaceae & Buah \\
2 & Cengkeh & Eugenia aromaticum & Myrtaceae & Bunga, Daun \\
3 & Jengkol & Pithecellobium lobatum & Fabaceae & Buah \\
4 & Petai & Perkia speciosa & Fabaceae & Buah \\
5 & Pala & Myristica fragrans & Myristicaceae & Buah \\
& & Artocarpus & & \\
6 & Nangka & heterophyllus & Moroceae & Buah \\
7 & Duku & Lansium domesticum & Meliaceae & Buah \\
8 & Alpukat & Persea americana & Lauraceae & Buah \\
9 & Kemiri & Aleurites moluccanus & Euphorbiceae & Buah \\
10 & Melinjo & Gnetum gnemon & Gnetaceae & Buah, Daun \\
11 & Mangga & Mangifera indica & Anacardiaceae & Buah \\
\hline \multicolumn{5}{l}{ Sumber:Data Primer 2019 }
\end{tabular}

HHBK dari tanaman MPTs yang terdapat di Hutan Desa Sukaraja ada yang dimanfaatkan buahnya namun ada juga yang dimanfaatkan bunga dan daunnya. Sebagian besar HHBK yang dipanen dijual walaupun ada juga yang dikonsumsi sendiri. Nawirat dkk (2008) menyebutkan tanaman MPTs yang paling umum ditanam masyarakat adalah durian (Durio zibethinus), rambutan, alpukat (Persea americana), nangka (Artocarpus heterophylus), mangga (Mangifera indica), kemiri (Aleurites moluccanus), sirsak, petai (Parkia spesiosa), cengkeh (Syzigium aromaticum), jambu air, jambu biji dan lainnya.

Hutan Desa Sukaraja, terletak pada ketinggian 0 - 1.000 mdpl. Kondisi ini sangat sesuai sebagai tempat tumbuh durian. Hasil penelitian Wiryata (2001), pohon durian dapat tumbuh baik pada ketinggian 1-800 mdpl, penelitian Soedarya (2009) yang menyatakan tempat tumbuh durian yang paling optimal adalah pada ketinggian 50-600 mdpl. Sebagian besar lahan di Hutan Desa Sukaraja (51,19 \%) berada pada kelerengan 9-15\% atau landai, pada kondisi ini pohon yang paling cocok ditanam berdasarkan kesesuaian tempat tumbuhnya adalah pohon durian. Soverdo (2010) yang menyebutkan bahwa durian cocok di tanam pada kondisi lahan berbukit dengan kemiringan kurang dari $15 \%$. Pada ketinggian ini juga sangat cocok bagipertumbuhan pohon cengkeh. Pohon cengkeh juga dapat tumbuh dan berproduksi apabila berada pada ketinggian 0-900 mdpl dan ketinggian yang paling optimal adalah pada 200- 600 mdpl.

Pemilihan jenis MPTs tersebut bertujuan untuk mengembalikan fungsi hutan agar menjadi lebih baik sehingga dapat meningkatkan penghasilan petani penggarap. Sedangkan bibit tanaman diperoleh dari bantuan KPH Rajabasa yang telah menyediakan persemaian (RPHJP, 2013).

\section{Potensi Tanaman MPTs Beberapa Tahun yang Akan Datang}

Potensi HHBK di Hutan Desa Sukaraja perlu diketahui guna menganalisis keberadaannya pada masa yang akan datang. Pengamatan 
dilakukan pada pohon fase tiang dan pancang. Jumlah MPTs yang diprediksi keberadaannya dimasa yang akan datang disajikan pada Tabel 3.

Tabel 3. Potensi HHBK dari Tanaman MPTs Beberapa Tahun yang Akan Datang

\begin{tabular}{|c|c|c|c|c|c|}
\hline \multirow[t]{2}{*}{ No. } & \multirow{2}{*}{$\begin{array}{l}\text { Nama } \\
\text { Lokal }\end{array}$} & \multirow{2}{*}{$\begin{array}{l}\text { Rata- } \\
\text { rata } \\
\text { thn } \\
\text { produksi }\end{array}$} & \multicolumn{2}{|c|}{$\begin{array}{l}\text { Prediksi MPTs pada masa yg akan } \\
\text { datang (individu) }\end{array}$} & \multirow[t]{2}{*}{ Jumlah } \\
\hline & & & $1-2$ thn & 3-4 thn & \\
\hline 1 & Durian & 6 & 10 & - & 10 \\
\hline 2 & Cengkeh & 5,3 & 12 & - & 12 \\
\hline 3 & Jengkol & 7,5 & 6 & 2 & 8 \\
\hline 4 & Petai & 7,6 & 3 & 2 & 5 \\
\hline 5 & Pala & 7 & 5 & 1 & 6 \\
\hline 6 & Nangka & 7 & 1 & - & 1 \\
\hline 7 & Duku & 8 & 1 & - & 1 \\
\hline 8 & Alpukat & 8,3 & 3 & 5 & 8 \\
\hline 9 & Kemiri & 7,6 & - & - & - \\
\hline 10 & Melinjo & 9 & 2 & - & 2 \\
\hline 11 & Mangga & 7 & - & - & - \\
\hline
\end{tabular}

Sumber : Data Primer 2019

Hasil penelitian menunjukkan bahwa pada beberapa tahun yang akan datang cengkeh (Syzigium aromaticum) merupakan komoditi yang banyak keberadaannya di Hutan Desa Sukaraja, dilihat dari besarnya jumlah cengkeh pada fase pancang dan tiang (Tabel 3). Hal ini diduga karena usia produksi cengkeh yang lebih cepat berproduksi dibandingkan dengan komoditi lain sehingga petani mengharapkan akan lebih cepat memperoleh hasil panen. Siregar (2011) mengatakan bahwa kondisi cengkeh di Indonesia mengalami pasang surut karena tingginya fluktuasi harga cengkeh. Karakteristik khas cengkeh yaitu cengkeh mengalami panen besar namun diikuti panen kecil di tahun berikutnya, kemudian ada kalanya cengkeh akan panen raya pada periode tertentu. Hal tersebut mengakibatkan petani rugi dan kurang melakukan perawatan sehingga produksi menjadi rendah. Akan tetapi bebeda dengan yang terjadi di Hutan Desa Sukaraja, prediksi keberadaan cengkeh untuk beberapa tahun yang akan datang merupakan yang tertinggi dibanding dengan jenis lain. Artinya cengkeh masih digemari oleh petani hingga beberapa tahun yang akan datang.

Akan tetapi, hal berbeda justru terjadi pada mangga (Mangifera indica). Hasil penelitian menunjukkan bahwa mangga merupakan HHBK dengan satuan produksi yang tertinggi, harga jual mangga juga tergolong cukup tingga sehingga dapat menghasilkan nilai ekonomi yang tinggi. Namun, mangga bukan merupakan tanaman yang akan dimanfaatkan oleh petani pada masa yang akan datang. Hal tersebut diduga karena masa simpan buah mangga pada pasca panen yang singkat.

Buah pasca panen merupakan kondisi buah yang terjadi setelah masa pemanenan dilakukan (Rukmana, 2003). Pada masa ini buah akan mengalami perubahan mutu baik secara fisik, kimia ataupun biologi. Mangga 
merupakan jenis buah klimakterik (Widodo, 2012), yaitu buah yang mengalami lonjakan respirasi dan produksi etilen setelah dipanen (Suhadirman, 1997). Artinya buah akan tetap mengalami pemasakan setelah masa pasca panen. Buah klimakterik adalah buah yang memiliki laju respirasi yang tinggi, laju respirasi berbanding terbalik dengan masa simpan buah (Widodo, 2012). Artinya, buah klimakterik adalah jenis buah yang memiliki masa simpan lebih cepat (Fenny, 2002). Sehingga, petani harus memiliki perhitungan waktu pemanenan dan pemasaran serta cara penyimpanan yang tepat agar tidak merugi (Rukmana, 2003).

\section{PENUTUP}

Kesimpulan yang diperoleh dari hasil penelitian adalah terdapat 11 jenis MPTs yang terdapat di Hutan Desa Sukaraja yaitu, durian (Durio zibethinus), Cengkeh (Eugenia aromaticum), jengkol (Artocarpus heterophyllus) duku (Lansium domesticum), alpukat (Persea americana) dan mangga (Mangifera indica). Pohon durian dan cengkeh merupakan pohon yang dipilih oleh petani penggarap Hutan Desa Sukaraja sebagai jenis yang paling banyak ditanam hingga beberapa tahun yang akan datang. Berdasarkan hasil penelitian mangga dan kemiri hingga 4 tahun yang akan datang akan hilang sehingga diperlukan pengayaan jenis potensial di Hutan Desa Sukaraja.

\section{DAFTAR PUSTAKA}

Arikunto, S. 2006. Prosedur Penelitian Suatu Pendekatan Praktek. Buku. PT Rineka Cipta. Jakarta.

Fenny, M. 2002. Bercocok Tanam Buah-Buahan. Buku. Aneka Ilmu.

Semarang. Fiqa, A.P dan Laksono, R.A. 2013. Pengembangan Sistem Agroforestri Berbasis Indigenous Spesies dan Kesesuaian Lahan di Wilayah Kabupaten Pasuruan Jawa Timur.Prosiding Seminar Nasional Agroforestri.

Ginoga, K., Mega, L. dan Deden, D. 2005. Kajian kebijakan pengelolaan hutan lindung. Jurnal Penelitian Sosial dan Ekonomi. 2 (2) : 203-232. Indriyanto. 2008. Pengantar Budi Daya Hutan. Bumi Aksara.Jakarta.

Indriyanto. 2013. Teknik dan Manajemen Persemaian. Buku. Lembaga Penelitia Universitas Lampung. Lampung. 270 hlmn.

Kurniawan,S.2018.ToleransiPohon.Artikel. $\quad$ https://slideplayer.info/slide/ 12144201/. Diakses pada Tanggal 3 Oktober 2019 pukul 20.30 WIB.

Mulyana, L., Febryano, I. G., Safe'i, R. dan Banuwa, I. S. 2017. Performa pengelolaan agroforestri di wilayah kesatuan pengelolaan hutan lindung rajabasa.J. Hutan Tropis. 5(2) :127-133.

Peraturan Kepala Desa Sukaraja. 2015. No 2 Tahun 2015 tentang Mekanisme dan Tata Cara Pembentukkan Lembaga Pengelola Hutan Desa (LPHD). Peraturan Kepala Desa. Sukaraja. 6 hlm.

Peraturan Pemerintah R.I. No 06. 2007. Tentang Tata Hutan Dan PenyusunanRencana Pengelolaan Hutan, Serta Pemanfaatan Hutan. Presiden Republik Indonesia. Jakarta 
Peraturan Perundangan Republik Indonesia. 1999. No. 41 Tahun 1999 tentang Kehutanan. Jakarta. Sekertariat Negara. 47 hlmn.

RPHJP KPHL Rajabasa. 2013. Rencana Pengelolaan Hutan Jangka Panjang (RPHJP) Kesatuan Pengelolaan Hutan Lindung (KPHL) Model Rajabasa Kabupaten Lampung Selatan Provinsi Lampung 2014-2023. RPHJP. Kalianda. 69 hlmn.

Prasetyo, B. H. 2005. Andisol: karakteristik dan pengelolaannya untuk pertanian di Indonesia. J. Sumberdaya Lahan.1 (1) : 1-9.

Rukmana, R. 2003. Mangga Budidaya dan Pascapanen. Buku. Kanisius. Yogyakarta. $107 \mathrm{hlmn}$.

Rukmana, R. 2004. Budidaya Alpukat. Buku. Kanisius. Yogyakarta. 68 hlmn. Simon, H. 2006. Hutan jati dan kemakmuran: Problema dan strategi pemecahannya. Buku. Pustaka Pelajar. Yogyakarta.

Siregar, A. R. 2011. Analisis Disparitas harga dan potensi persaingan tidak sehat pada distribusi cengkeh. Jurnal Agribisnis. 10 (3) : 32-34.

Soedarya, A. P. 2009. Budidaya Usaha Pengolahan Agribisnis Durian.Buku. Pustaka Grafika : Bandung.

Soil Survey Staff. 2010. Key to Soil Taxonomy. Andosols. Van Nostrand Reinhold Company. New York. 418 hlm.

Suhadirman. 1997. Penanganan dan Pengolahan Buah Pasca Panen. Buku. Penebar Swadaya. Jakarta.

Surat Keputusan Menteri Kehutanan Republik Indonesia. 2011. No 367/Menhut-II/2011 tentang Penetapan Wilayah Kesatuan Pengelolaan Hutan Lindung (KPHL) Model Rajabasa (Unit XIV) yang Terletak di Kabupaten Lampung Selatan Provinsi Lampung. Jakarta. Sekertariat Negara. 4 hlmn.

Susanto, H. 2002. Budidaya Kemiri Komoditas Ekspor. Buku. Kanisius. Yogyakarta. $69 \mathrm{hlmn}$.

Violita, C. Y., Setiawan, A. dan Rustiati, E. L. 2015.Ukuran kelompok simpai (presbytis melalophos) di hutan desa cugung kesatuan pengelolaan hutan lindung model gunung rajabasa lampung selatan.J.Sylva Lestari.3 (3) : 11-18.

Widodo, S. E. 2012. Memahami Panen dan Pascapanen Buah. Buku. Lembaga Penelitian Universitas Lampung. Lampung. $145 \mathrm{hlmn}$.

Wiryanta, B. T. W. 2001. Bertanam Durian. Buku.AgroMedia Pustaka. Jakarta. 